\title{
An unusual and malignant intussusception in a child
}

\author{
Gabriella D'Angelo ${ }^{1,4,5^{*}}$, Lucia Marseglia ${ }^{1,4}$, Marta Manti ${ }^{2}$, Giovanni Stroscio ${ }^{2}$, Daniela Impollonia ${ }^{2}$, Salvatore Arena ${ }^{3}$, \\ Pietro Impellizzeri ${ }^{3}$, Carmelo Salpietro ${ }^{2}$, Carmelo Romeo ${ }^{3}$ and Eloisa Gitto ${ }^{1,4}$
}

\begin{abstract}
Intussusception is a common cause of bowel obstruction in the pediatric population. Malignant lesions account for up to $30 \%$ of all cases of intussusception in the small intestine. We herein report an interesting case of ileo-colic intussusception caused by diffuse large B-cell lymphoma, in a child. The patient underwent laparoscopic right hemicolectomy. Pathologic evaluation revealed a diffuse large B-cell lymphoma. In cases of intussusception, especially in the older age group of children, a high index of suspicion for malignant lymphoma of the bowel should be observed.
\end{abstract}

Keywords: Malignant tumour, Small intestine, Bowel obstruction, Surgery, Child

\section{Dear editor}

Intussusception, defined as the telescoping of a segment of the gastrointestinal tract into an adjacent one, is often seen in paediatric age [1]. Gastrointestinal tumours, especially if they occur in the large bowel, cause intestinal intussusception in 63-68\% of cases [2]. Intussusception caused by diffuse large B-cell lymphoma (DLBCL), as a cause of acute abdomen, is rare, and, often, intussusception represents the first clinical sign, leading, potentially, to disease detection at an early stage [3].

We herein present a rare case of an ileo-colic intussusception caused by DLBCL in a pediatric patient who initially underwent surgical treatment and, subsequently, adjuvant chemotherapy. An 8-year-old boy presented with previous medical history of abdominal pain and nausea with vomiting following meals. Symptoms progressively worsened to severe anorexia, weight loss, constipation, and bilious vomiting, on the day of admission. Fever, chills, bleeding per rectum, and previous abdominal surgeries were absent. Laboratory tests only showed increased C-reactive protein $(2.5 \mathrm{mg} / \mathrm{L}$, normal range 0 $0.5 \mathrm{mg} / \mathrm{L}$ ). Abdominal X-ray revealed no specific bowel gas pattern, but with gaseous distension of several small

\footnotetext{
* Correspondence: gabridangelo@alice.it

${ }^{1}$ Neonatal and Pediatric Intensive Care Unit, Department of Pediatrics,

University of Messina, Messina, Italy

${ }^{4}$ Neonatal Intensive Care Unit, Department of Pediatrics, University of

Messina, Messina, Italy

Full list of author information is available at the end of the article
}

bowel loops. Focused sonography of the right lower quadrant reported a "target sign" or "doughnut", pseudokidney/ sandwich appearance [Fig. 1], suggesting bowel intussusception. Abdominal computed tomography (CT) revealed a typical target-appearing lesion, extending for approximately $16 \mathrm{~cm}$ of the terminal ileum and ascending colon into the transverse colon. Liver metastasis was also described. Emergency laparotomy confirmed a distal ileo-colic intussusception. Laparotomy was performed and an ileo-colic intussusception noted with a $4 \mathrm{~cm} \times 4 \mathrm{~cm}$ intraluminal growth in the lumen, a large and hard mesenteric mass. Enlarged mesenteric lymphnodes were also detected [Fig. 2]. The involved segment presented edema and initial necrosis with loss of the classic three-layer intestinal mucosa. It was resected with $5 \mathrm{~cm}$ margins, and end to end anastomosis was performed on the healthy small bowel. In the follow-up period, the patient underwent contrast enhanced CT scan of the thorax, abdomen and pelvis to look for synchronous lesions detected on admission (hepatic lesions). The child was thereafter referred to the Medical Oncology and Radiation Oncology Department where he underwent adjuvant chemotherapy and is under fortnightly follow-ups. The leading point of the invagination was a DLBCL measuring $4 \times 4 \mathrm{~cm}$, consisting of centroblastic/polymorphic cells of intermediate-large size; CD20+, CD10+, bcl2-, bcl6+, CD5-, D1, CKAE1-AE3, AML-. 


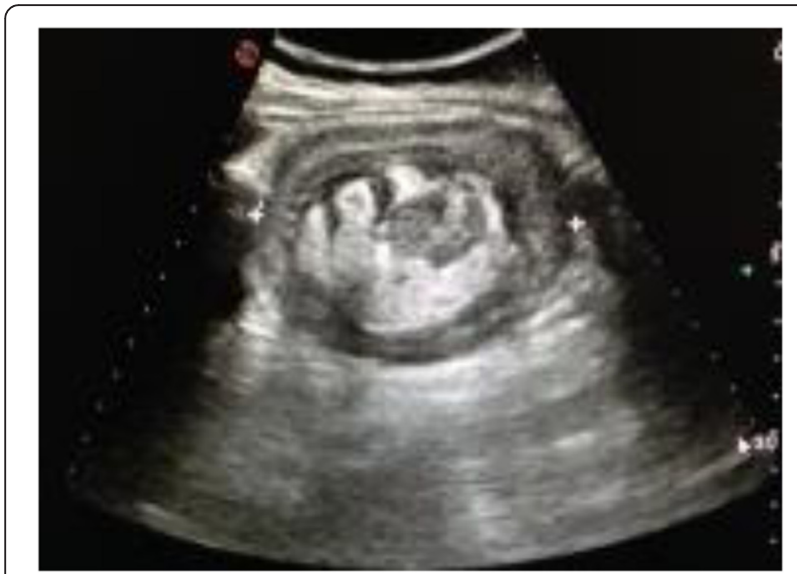

Fig. 1 Abdominal ultrasound noted an intussusception, giving the typical "target" sign

MIB $>70 \%$. All nodes showed reactive hyperplastic follicle-sinus histiocytosis and lymphostasis.

Primary malignant tumours of the small intestine are very rare, accounting for less than $2 \%$ of all gastrointestinal malignancies [2]. Lymphoma constitutes 15$20 \%$ of all small intestine neoplasms [4]. In particular, DLBCL, the most common form of non-Hodgkin lymphoma (NHL), is a heterogeneous entity rarely causing acute obstructive symptoms and intussusceptions [5]. Intestinal involvement of NHL has been correlated to increased frequency of abdominal symptoms resulting in an earlier diagnosis. It was found that the invasion depth of the tumour is significantly associated with patient survival [6]. DLBCL-patients initially undergo chemotherapy rather than surgery. Therefore, the relationship between surgery treatment and prognosis has not previously been reported. The importance of resection of the bowel containing even the smallest of lesions, along with removal of regional lymph nodes,

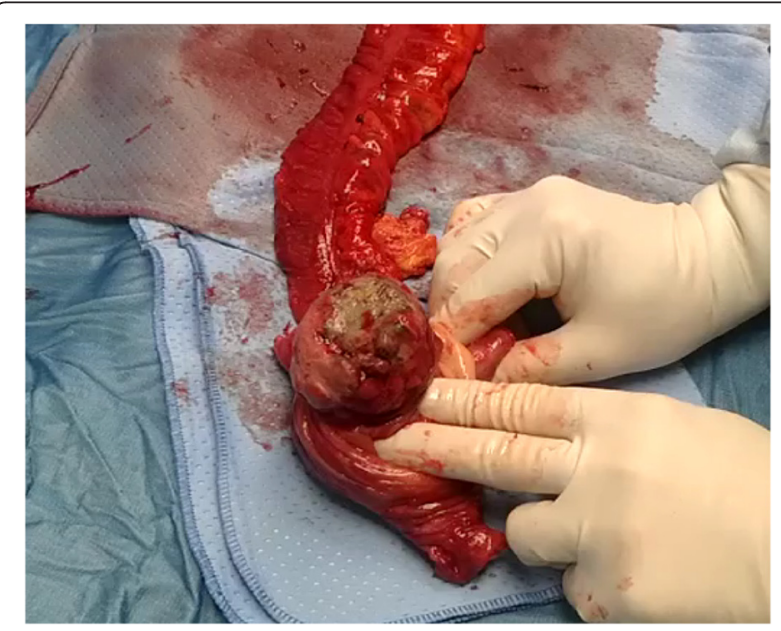

Fig. 2 Resected specimen showing the large B-cell lymphoma is further stressed [7]. Moreover, a multicenter study found that primary surgical resection was associated with a favourable prognosis in cases of intestinal DLBCL, encouraging surgical resection as primary treatment [8]. Conversely, an increased risk of gastric adenocarcinoma after treatment of primary gastric lymphoma has been also reported, especially of diffuse large B-cell lymphoma [9]. Finally, there is no consensus on the optimal treatment against primary gastrointestinal DLBC $[5,6]$.

In conclusion, we describe a pediatric case of large Bcell lymphoma causing an ileo-colic intussusception. In cases of intussusception, especially in the older age group of children, a high index of suspicion for malignant lymphoma of the bowel, including DLBCL should be observed.

\section{Abbreviations}

$\mathrm{CT}$, computed tomography; DLBCL, diffuse large B-cell lymphoma; NHL, nonhodgkin lymphoma

\section{Acknowledgements}

The authors are grateful to the patient and his family for their support for our article.

\section{Financial disclosure}

The authors declare that they have no sources of funding.

\section{Availability of data and materials}

All clinical data and supporting materials concerning the manuscript are available in case of Editorial request.

\section{Authors' contributions}

GD Study conception and design of the manuscript. LM, SM Writing up of first draft of the paper. GS, DI Conceived the paper. SA, PI Helped draft the manuscript. CS Critical revision of the article. CR Critical revision of the article. EG Approved final manuscript. All authors read and approved the final manuscript.

\section{Competing interests}

The authors declare that they have no competing interests.

\section{Ethics approval and consent to participate}

Written informed consent was obtained from the patient's parents for publication of this paper and accompanying images. A copy of the written consent is available for review by the Editor-in-Chief of this journal.

\section{Author details}

${ }^{1}$ Neonatal and Pediatric Intensive Care Unit, Department of Pediatrics, University of Messina, Messina, Italy. ${ }^{2}$ Unit of Paediatric Genetics and Immunology, Department of Paediatrics, University of Messina, Messina, Italy. ${ }^{3}$ Unit of Paediatric Surgery, Department of Paediatrics, University of Messina, Messina, Italy. ${ }^{4}$ Neonatal Intensive Care Unit, Department of Pediatrics, University of Messina, Messina, Italy. ${ }^{5}$ Department of Pediatrics, University of Messina, Via Consolare Valeria, 1, 98125 Messina, Italy.

Received: 27 June 2016 Accepted: 25 July 2016

Published online: 01 August 2016

\section{References}

1. Mehendale S, Kumar CP, Venkatasubramanian S, Prasanna T. Intussusception in Children Aged Less than Five years. Indian J Pediatr. 2016. [Epub ahead of print].

2. $B k G, H m$ Q, Pk C, Tan $K$, Tay $K$, Kw E, et al. Predictive factors of malignancy in adults with intussusception. World J Surg. 2006:30:1300-4.

3. Akbulut $\mathrm{S}$. Unusual cause of adult intussusception: diffuse large B-cell nonHodgkin's lymphoma: a case report and review. Eur Rev Med Pharmacol Sci. 2012;16:1938-46. 
4. Ghimire P, Wu GY, Zhu L. Primary gastrointestinal lymphoma. World J Gastroenterol. 2011;17:697-707.

5. Xu XQ, Hong T, Li BL, Liu W. lleo-ileal intussusception caused by diffuse large B-cell lymphoma of the ileum. World J Gastroenterol. 2013;19:8449-52

6. Stein H, Warnke RA, Chan WC, Jaffe ES, Chan JKC, Gatter KC, Campo E, et al. Diffuse large B-cell lymphoma, not otherwise specified. In: Swerdlow SH, Campo E, Harris NL, editors. WHO classification of tumours of haematopoietic and lymphoid tissues. 4th ed. Lyon, France: IARC; 2008. p. 233-7.

7. Simpson T, Ivey J, Borkowski S. Pediatric management problems. Intussusception Pediatr Nurs. 2004;30:326-7.

8. Kim SJ, Kang HJ, Kim JS. Comparison of treatment strategies for patients with intestinal diffuse large B-cell lymphoma: surgical resection followed by chemotherapy versus chemotherapy alone. Blood. 2011;117:1958.

9. Inaba K, Kushima R, Murakami N, Kuroda Y, Harada K, Kitaguchi M, et al. Increased risk of gastric adenocarcinoma after treatment of primary gastric diffuse large B-cell lymphoma. BMC Cancer. 2013;13:499.

Submit your next manuscript to BioMed Central and we will help you at every step:

- We accept pre-submission inquiries

- Our selector tool helps you to find the most relevant journal

- We provide round the clock customer support

- Convenient online submission

- Thorough peer review

- Inclusion in PubMed and all major indexing services

- Maximum visibility for your research

Submit your manuscript at www.biomedcentral.com/submit
Biomed Central 